\title{
Need to Consider Variations within Demographic Groups When Evaluating Educational Interventions
}

\author{
Amruth N. Kumar \\ Ramapo College of New Jersey \\ 505 Ramapo Valley Road \\ Mahwah, NJ 07430, USA \\ 12016847712 \\ amruth@ramaop.edu
}

\begin{abstract}
Traditionally, educational interventions in Computer Science have been studied for their effect on entire classes, or specific demographic groups. But, in our studies, we have found that often, significant interactions exist among demographic groups. Treating demographic groups as homogeneous groups when evaluating educational interventions in Computer Science could miss subtle interactions among the groups.
\end{abstract}

\section{Categories and Subject Descriptors}

K.3.1. [Computing Milieux]: Computer-Assisted Instruction

\section{General Terms}

Experimentation.

\section{Keywords}

Evaluation, Demographics, Interaction

\section{INTRODUCTION}

Computer Science educators and researchers have traditionally evaluated educational interventions, such as new courseware and new ways to teach courses, in classroom settings. They have presented results in terms of improvement of learning of "the class" (examples from SIGCSE/ITiCSE 08 include $[2,6,8]$ ). Some educators and researchers have further analyzed the data to see if the interventions were particularly helpful to certain "demographic groups" (examples from SIGCSE/ITiCSE 08 include $[3,4,5,7])$. Sex, academic status, race, etc. are some of the demographic groups that have been more commonly considered during such analysis. Typically, these groups have been treated as being homogeneous, i.e., Computer Science educators have presented results in terms of an entire demographic group (e.g., male students), and have not typically reported variations within a group (e.g., freshman versus senior male students). This paper presents examples of evaluation that show that variations exist within demographic groups, and therefore, Computer Science

Permission to make digital or hard copies of all or part of this work for personal or classroom use is granted without fee provided that copies are not made or distributed for profit or commercial advantage and that copies bear this notice and the full citation on the first page. To copy otherwise, or republish, to post on servers or to redistribute to lists, requires prior specific permission and/or a fee.

ITiCSE'09, July 6-9, 2009, Paris, France.

Copyright 2009 ACM 978-1-60558-381-5/09/07 ...\$5.00. educators may want to consider such variations when evaluating their educational interventions.

The work presented here started out as a study of the differences, if any, among the users of online software tutors, called problets (www.problets.org), that were developed to help introductory Computer Science students learn programming concepts by solving problems. The study looked into whether differences existed among tutor users based on sex, academic status, race, major and the type of institution (2-year versus 4-year college). Data collected by the software tutors in spring and fall 2007 was analyzed for the study. Some of the results were easy to explain, such as students from 4-year institutions had more prior selfconfidence than those from 2-year institutions and that the earlier the students were in the academic track, the more practice they needed with the tutors. But, other results that allude to variations within demographic groups were surprising, and lead to the primary contribution of this paper - that variations within demographic groups may have to be considered when evaluating educational interventions in Computer Science.

In Section 2, the demographic study will be described. In Section 3, the primary results of the demographic study, many of which are intuitive, will be presented. In Section 4, the variations within demographic groups will be presented, followed by discussion in Section 5.

\section{THE DEMOGRAPHIC STUDY}

The demographic study included four dependent variables (prior preparation, prior self-confidence, need for practice, and interest in using tutors); five demographic groups (status, sex, race, major, and type of institution); and data collected by two software tutors (on arithmetic expression evaluation and selection statements) over two semesters (spring and fall 2007).

The software tutors were set up to administer the following stages:

1. Registration, wherein, the student entered demographic data including name, sex, race, major, and academic status.

2. Pre-Survey, wherein the student was asked to rate her/his knowledge of the topic on a Likert scale of 1 (Very well) to 5 (Not at all).

3. Pre-test, wherein the student answered a fixed number of problems on the topic. 
4. Adaptive practice, wherein the student was administered additional problems on only the concepts on which the student had made mistakes during the pre-test. Students who correctly solved all the pre-test problems got no practice at all. Students who solved problems on a concept incorrectly during pretest were given repeated practice problems on the concept until they solved at least $60 \%$ of the problems correctly.

5. Adaptive post-test on only the concepts on which a student answered practice problems.

6. Feedback, which consisted of 14 statements on the usability, ability to learn from, and the usefulness of the tutor - the student was asked to respond to each statement on a Likert scale of 1 (Strongly agree) to 5 (Strongly disagree).

7. Post-Survey, which administered the pre-survey again.

The four dependent variables considered for the study were defined as follows:

1. Prior preparation: The average score per problem on the pretest is a measure of the prior preparation of the students.

2. Prior self-confidence: The most general statement on the presurvey, viz., "How well do you know arithmetic operators?", and "How well do you know 'if-else' statements?" was used as a measure of the prior self-confidence of the students. Students responded to the statement on a Likert scale of 1 (Very well) to 5 (Not at all).

3. Need for practice: Since the tutor was adaptive, the number of problems answered by the student during practice was a measure of who needed the most practice with the tutor. The number of problems was influenced not only by the pre-test score, but also by the rate at which the student learned. Since not every student needed/got practice, the total sample size was smaller for this analysis.

4. Interest in using tutors: The response of the student on the statement in the feedback form - "I would like to see such tutors on other topics" was used as indicative of the student's interest in using such tutors. Again, the response was on a Likert scale of 1 (Strongly agree) to 5 (Strongly disagree).

Since not all the students filled out the self-confidence survey and/or the feedback form, sample sizes varied on dependent variables 2 and 4.

The demographic data collected by the software tutors, as selfreported by the students who used the tutors, were:

1. Status - freshman, sophomore, junior, senior and nonmatriculate. In the tables to follow, for the sake of brevity, these are referred to as I, II, III, IV and X respectively.

2. Sex - male and female.

3. Race - Caucasian and non-Caucasian. Non-Caucasians included Black/African American, Hispanic/Latino, Asian, Native American, Native Hawaiian/Pacific Islander and Other.

4. Major - Computer Science, Information Systems, and Other. Other majors included Other Sciences (Physics/Chemistry/Biology/Other), Business, Social Sciences, Arts, Humanities, and Other.
5. Type of institution - 4-year and 2-year college. In the United States, 4-year colleges offer baccalaureate degrees. 2-year colleges offer associate degrees. Their graduates transfer to a 4-year college for their junior and senior years.

Two tutors that provided two different types of problems were used for this study, to see if there was consistency within a population across tutors:

1. Tutor on arithmetic expressions in which students had to evaluate arithmetic expressions one operator at a time.

2. Tutor on selection statements in which students had to predict the output of programs that contained if and if-else statements.

Finally, data from two semesters: spring 2007 and fall 2007, was analyzed to see if there were consistent patterns across populations.

In spring 2007, the arithmetic tutor was used by 274 students from 10 schools, 3 of which were 2-year colleges. The selection tutor was used by 225 students from 10 schools, 4 of which were 2 -year colleges. In fall 2007, the arithmetic tutor was used by 270 students from 12 schools, 3 of which were 2 -year colleges. The selection tutor was used by 214 students from 13 schools, 4 of which were 2-year colleges. The students used the online tutors on their own time, as directed by their instructors. The data from the tutors was collected over the web.

A $5 \times 2 \times 2 \times 3 \times 2$ ANOVA analysis of the data was conducted, with status (freshman, sophomore, junior, senior and non-matriculate), sex (male, female), race (Caucasian, nonCaucasian), major (Computer Science, Information Systems, Other) and institution (4-year college, 2-year college) as fixed factors. In the following analysis, the sample size will always be presented, so that the patterns identified or the conclusions drawn can be kept in perspective. Conclusions will be limited to the cases wherein the sample size is at least $10-15$ subjects per subgroup (e.g., female Computer Science sophomores).

\section{MAIN EFFECTS}

What follows are the main effects for individual demographic groups on the four dependent variables - prior preparation, prior self-confidence, need for practice and interest in using tutors.

\subsection{Prior Preparation}

Race was a significant factor on the arithmetic tutor in fall 2007 $[F(1,218)=6.044, p=0.015]$ : Caucasian students were better prepared than non-Caucasian students as shown in the table below, i.e., Caucasian students solved $86 \%$ of each problem correctly whereas non-Caucasian students solved $74.2 \%$ correctly.

\begin{tabular}{|l|c|c|}
\hline Arithmetic/Fall 07 & Caucasian & Non-Caucasian \\
\hline $\mathrm{N}$ & 130 & 89 \\
\hline Ave & 0.860 & 0.742 \\
\hline
\end{tabular}

No other significant factor was found accounting for prior preparation on any other tutor/semester.

\subsection{Prior Self-Confidence}

The type of institution (4-year versus 2-year) was a significant factor on the arithmetic tutor $[F(1,188)=5.006, p=0.027]$ as well 
as the selection tutor $[\mathrm{F}(1,147)=5.062, \mathrm{p}=0.027]$ used in fall 2007. In both cases, 4-year students had greater prior selfconfidence than 2-year students as shown in the table below, e.g., on the arithmetic tutor in fall 2007, on a Likert scale of 1 (Very well) to 5 (not at all), the average response of 4-year students on the question "How well do you know arithmetic expressions" was 1.878 , i.e., closer to 'Very well' than the average response of 2 year students (2.241).

\begin{tabular}{|l|c|c|}
\hline Arithmetic/Fall 07 & 4-year & 2-year \\
\hline N & 159 & 30 \\
\hline Ave & 1.878 & 2.241 \\
\hline Selection/Fall 07 & 4-year & 2-year \\
\hline N & 127 & 21 \\
\hline Ave & 2.506 & 2.958 \\
\hline
\end{tabular}

Major was also a significant factor on the selection tutor in fall $2007[\mathrm{~F}(2,147)=4.150, \mathrm{p}=0.019]$ : Computer Science students had greater prior self-confidence than students from other majors, as shown in the table below.

\begin{tabular}{|l|c|c|c|}
\hline Major & $\begin{array}{l}\text { Computer } \\
\text { Science }\end{array}$ & $\begin{array}{l}\text { Information } \\
\text { Systems }\end{array}$ & Other \\
\hline $\mathrm{N}$ & 43 & 26 & 79 \\
\hline Ave & 2.379 & 2.763 & 2.764 \\
\hline
\end{tabular}

\subsection{Need for Practice}

Race was a significant factor on both arithmetic tutor $[\mathrm{F}(1,123)=$ 4.962, $\mathrm{p}=0.030]$ and selection tutor $[\mathrm{F}(1,130)=5.714, \mathrm{p}=$ 0.019] used in spring 2007. In both the cases, Caucasian students needed less practice than non-Caucasian students, as shown in the table below, e.g., on the selection tutor in spring 2007, Caucasian students answered an average of 7.599 problems whereas nonCaucasian students answered an average of 10.799 problems during practice. Since practice was adaptive, these numbers represent the prior preparation of these students as well as how quickly they learned the concepts underlying the problems.

\begin{tabular}{|l|c|c|}
\hline Arithmetic/Spring 07 & Caucasian & Non-Caucasian \\
\hline N & 78 & 46 \\
\hline Ave & 15.764 & 15.874 \\
\hline Selection/Spring 07 & Caucasian & Non-Caucasian \\
\hline N & 77 & 54 \\
\hline Ave & 7.599 & 10.799 \\
\hline
\end{tabular}

Status was a significant factor on arithmetic tutor in spring 2007 $[F(4,123)=3.767, p=0.008]$ : the earlier the students were in the academic track, the more practice they needed with the tutor. Recall that freshman is designated as I, senior as IV and nonmatriculate as $\mathrm{X}$ in the following tables.

\begin{tabular}{|l|c|c|c|c|c|}
\hline Spr07 & I & II & III & IV & X \\
\hline $\mathrm{N}$ & 36 & 37 & 28 & 12 & 11 \\
\hline Ave & 21.597 & 14.831 & 14.725 & 8.083 & 5.833 \\
\hline
\end{tabular}

Major was also a significant factor $[\mathrm{F}(2,123)=4.322, \mathrm{p}=0.018]$. Surprisingly, Computer Science students needed more practice than their counterparts in other majors.

\begin{tabular}{|l|c|c|c|}
\hline $\begin{array}{l}\text { Arith/ } \\
\text { Spr 07 }\end{array}$ & $\begin{array}{c}\text { Computer } \\
\text { Science }\end{array}$ & $\begin{array}{c}\text { Information } \\
\text { Systems }\end{array}$ & Other \\
\hline $\mathrm{N}$ & 31 & 21 & 72 \\
\hline Ave & 16.478 & 15.979 & 15.412 \\
\hline
\end{tabular}

In retrospect, many of these results are intuitive. Their existence confirms that differences do exist among different demographic groups. That these results were not observed on all the tutors in all the semesters suggests that they cannot be overly generalized.

\section{SIGNIFICANT INTERACTIONS}

In ANOVA analysis, an interaction is said to occur between two factors if, for a given characteristic such as prior preparation, the lines for the different values of one factor (e.g., male and female for sex) intersect (with or without extrapolation) when plotted against the values of another factor (e.g., 2-year and 4-year institutions) - e.g., the prior preparation of 2-year males is less than that of 2-year females, but the prior preparation of 4-year males is greater than that of 4-year females. Such interactions indicate variations within demographic groups (e.g., males, or 2year students). Such interactions are considered statistically significant when their occurrence due to chance is less than $5 \%$. What follows are some of the significant interactions between demographic groups on the four characteristics - prior preparation, prior self-confidence, need for practice and interest in using tutors.

\subsection{Prior Preparation}

There was significant interaction between status and sex on the arithmetic tutor in spring $2007[\mathrm{~F}(4,217)=2.639, \mathrm{p}=0.036]$ : whereas male students were better prepared at the freshman level $(81.9 \%$ versus $78.5 \%$ correct), female students were better prepared at the sophomore level $(92.2 \%$ versus $88.3 \%$ correct). In this table (and in following tables as warranted), data for senior and non-matriculate students was not included when the sample size was small.

\begin{tabular}{|l|l|c|c|c|}
\hline \multicolumn{2}{|l|}{ Arithmetic/S07 } & I & II & III \\
\hline Male & N & 46 & 60 & 33 \\
\cline { 2 - 5 } & Ave & 0.819 & 0.883 & 0.902 \\
\hline \multirow{3}{*}{ Female } & $\mathrm{N}$ & 17 & 15 & 12 \\
\cline { 2 - 5 } & Ave & 0.785 & 0.922 & 0.856 \\
\hline
\end{tabular}

A similar significant interaction was found on the selection tutor in fall $2007(\mathrm{~F}[3,162]=4.349, \mathrm{p}=0.006]$ : male and female sophomores were equally prepared, but female juniors were much better prepared than male juniors. 


\begin{tabular}{|l|l|c|c|c|}
\hline \multicolumn{2}{|c|}{} & I & II & III \\
\hline Male & $\mathrm{N}$ & 27 & 38 & 24 \\
\cline { 2 - 5 } & Ave & 0.836 & 0.729 & 0.696 \\
\hline Female & $\mathrm{N}$ & 10 & 25 & 19 \\
\cline { 2 - 5 } & Ave & 0.578 & 0.722 & 0.835 \\
\hline
\end{tabular}

This could be a result of the shrinking pipeline [1] - female students who persist could be self-selected and better prepared.

There was significant interaction between race and major on the arithmetic tutor in spring $2007[\mathrm{~F}(2,217)=3.924, \mathrm{p}=0.022]$ : whereas among Computer Science majors, Caucasian students were better prepared than their non-Caucasian counterparts, among other majors, non-Caucasian students were better prepared than Caucasian students. (In the table, Information Systems major has been excluded due to small sample size.)

\begin{tabular}{|l|l|c|c|}
\hline \multicolumn{2}{|l|}{ Arithmetic/Spring 07 } & Computer Science & Other Majors \\
\hline Caucasian & $\mathrm{N}$ & 40 & 75 \\
\cline { 2 - 4 } & Ave & 0.933 & 0.819 \\
\hline Non-Caucasian & $\mathrm{N}$ & 31 & 40 \\
\cline { 2 - 4 } & Ave & 0.882 & 0.885 \\
\hline
\end{tabular}

There was significant interaction between status and race on the arithmetic tutor in fall $2007[\mathrm{~F}(3,218)=2.607, \mathrm{p}=0.053]$ - nonCaucasian student average improved from freshman to junior levels whereas the average of Caucasian students remained about the same, as shown in the table below.. (In the table, other academic levels have been excluded due to small sample size.) This pattern could have resulted from non-Caucasian students having more room to improve. But, no ceiling effect was observed among Caucasian students, i.e., Caucasian students had room to improve too (up to 1.0), but they did not. Alternatively, the pattern may have resulted from retention of only the better prepared non-Caucasian students through the academic pipeline, just as in the case of female students.

\begin{tabular}{|l|l|c|c|c|}
\hline \multicolumn{2}{|l|}{ Arithmetic/Fall 07 } & I & II & III \\
\hline Caucasian & N & 33 & 38 & 37 \\
\cline { 2 - 5 } & Ave & 0.859 & 0.829 & 0.846 \\
\hline Non-Caucasian & N & 19 & 38 & 22 \\
\cline { 2 - 5 } & Ave & 0.667 & 0.730 & 0.792 \\
\hline
\end{tabular}

\subsection{Prior Self-Confidence}

There was significant interaction between sex and race on arithmetic tutor in spring $2007[\mathrm{~F}(1,193)=7.673, \mathrm{p}=0.006]$ : Caucasian males were more self-confident than their female counterparts and non-Caucasian females were more self-confident than their male counterparts. This pattern eludes explanation.

\begin{tabular}{|l|l|c|c|}
\hline Arithmetic/Spr 07 & Caucasian & Non-Caucasian \\
\hline Male & $\mathrm{N}$ & 86 & 61 \\
\hline & Ave & 2.022 & 2.221 \\
\hline Female & $\mathrm{N}$ & 31 & 16 \\
\hline & Ave & 2.501 & 1.933 \\
\hline
\end{tabular}

\subsection{Interest in using Tutors}

There was significant interaction between race and major on arithmetic tutor in spring $2007[\mathrm{~F}(2,182)=5.675, \mathrm{p}=0.004]$ : Students in other majors were more interested in using tutors than their counterparts in Computer Science, as shown in the table below, e.g., on a Likert scale of 1 (Strongly agree) to 5 (Strongly disagree), the average response of Caucasian students with other majors (1.938) was closer to 'Strongly agree' than the average response of Caucasian Computer Science majors (2.169).to the statement "I would like to see such tutors on other topics." In the table, Information Systems major was dropped due to small sample size.

\begin{tabular}{|l|l|c|c|}
\hline \multicolumn{2}{|l|}{ Arithmetic/Spr. 07 } & Computer Science & Other Majors \\
\hline Caucasian & $\mathrm{N}$ & 36 & 66 \\
\hline & Ave & 2.169 & 1.938 \\
\hline Non-Caucasian & $\mathrm{N}$ & 23 & 36 \\
\hline & Ave & 2.130 & 1.908 \\
\hline
\end{tabular}

There was significant interaction between status and major $[\mathrm{F}(4,182)=2.996, \mathrm{p}=0.022]$ : non-Computer Science majors were more interested in using software tutors than Computer Science majors in the first two years, but not the junior year. (In the table, other years were dropped due to small sample size.).

\begin{tabular}{|l|l|c|c|c|}
\hline \multicolumn{2}{|l|}{ Arithmetic/Fall 07 } & I & II & III \\
\hline Computer Science & N & 23 & 20 & 12 \\
\cline { 2 - 5 } & Ave & 2.286 & 2.208 & 2.031 \\
\hline \multirow{2}{*}{ Other } & N & 20 & 33 & 26 \\
\cline { 2 - 5 } & Ave & 2.110 & 1.851 & 2.267 \\
\hline
\end{tabular}

The interaction between sex and major on the arithmetic tutor in fall 2007 was also significant $[\mathrm{F}(2,182)=3.164, \mathrm{p}=0.046]$. Among students of other majors, female students were more interested in using software tutors than their male counterparts, whereas, among Computer Science students, male students may have been more interested in using software tutors than their female counterparts (the relatively small sample size of female Computer Science students being a confound).

\begin{tabular}{|l|l|c|c|}
\hline \multicolumn{2}{|l|}{ Arithmetic/F07 } & Computer Science & Other Majors \\
\hline \multirow{2}{*}{ Male } & $\mathrm{N}$ & 48 & 43 \\
\cline { 2 - 4 } & Ave & 2.025 & 2.142 \\
\hline \multirow{2}{*}{ Female } & $\mathrm{N}$ & 12 & 57 \\
\cline { 2 - 4 } & Ave & 2.167 & 1.938 \\
\hline
\end{tabular}


Finally, there was significant interaction between major and the type of institution $[\mathrm{F}(2,182)=2.934, \mathrm{p}=0.057]$ on arithmetic tutor in fall 07: Computer Science students in 2-year colleges were less interested in using the software tutors than their 4-year counterparts. Students with other majors did not exhibit this difference across the types of institutions, as shown below.

\begin{tabular}{|l|l|c|c|}
\hline \multicolumn{2}{|l|}{ Arithmetic/F07 } & Computer Science & Other Majors \\
\hline 4-year & $\mathrm{N}$ & 45 & 89 \\
\hline & Ave & 1.877 & 2.036 \\
\hline 2-year & $\mathrm{N}$ & 15 & 11 \\
\hline & Ave & 2.444 & 2.050 \\
\hline
\end{tabular}

\section{DISCUSSION}

Many of the main effects were intuitive: 4-year students had greater prior self-confidence than 2-year students; Computer Science students had greater prior self-confidence than students from other majors; and the earlier the students were in the academic track, the more practice they needed with the tutor. However, most of the interactions among demographic groups were unexpected: 1) male students were better prepared than female students early in the academic pipeline, whereas female students were better prepared than male students later in the pipeline, presumably because of self-selection of female students as they worked through the shrinking pipeline; 2) among Computer Science majors Caucasian students were better prepared than their non-Caucasian counterparts, whereas among other majors, non-Caucasian students were better prepared than their Caucasian counterparts; 3) non-Caucasian student average improved from freshman to junior levels whereas the average of Caucasian students remained about the same - either because non-Caucasian students had more room to improve to begin with, or because only better-prepared non-Caucasian students persisted through the academic pipeline; 4) Caucasian males were more self-confident than their female counterparts and non-Caucasian females were more self-confident than their male counterparts; 5) Students in other majors were more interested in using tutors than their counterparts in Computer Science; 6) Computer Science students in 2-year colleges were less interested in using software tutors than their 4-year counterparts.

All of these are patterns that need further investigation. Some of these patterns may be purely an artifact of the software tutors or the specific population that used the tutors that semester. Others may be generalized to the broader population. Further collection and evaluation of data is needed to determine which patterns can be generalized and which ones cannot. The patterns reported in this paper could serve as the starting point for future evaluations.

The one definitive conclusion that can be drawn from the study is that significant interactions exist among the various demographic groups (sex, race, major, status, and type of institution). The results of the interactions are often unexpected. Treating demographic groups as homogeneous groups when evaluating educational interventions such as software tutors in Computer Science could miss subtle interactions among the groups. This result generalizes the intra-gender differences reported in literature [9].

Some implications are: 1) when studying the difference between two groups based on one demographic criterion, e.g., 4year versus 2-year students, researchers must ensure similar distributions in the two groups along the other demographic criteria, e.g., same ratio of male and female students, and/or Computer Science versus non-Science majors; 2) after narrowing the possibilities by studying interactions among demographic groups, researchers may want to focus on comparing two or more "multiply-qualified" groups, e.g., sophomore females versus freshman males; and 3) the distribution of data points in the hyperspace whose axes are the various demographic criteria might not only be interesting to study, it may also provide some key insights into online learning.

\section{ACKNOWLEDGMENTS}

Partial support for this work was provided by the National Science Foundation under grant DUE-0817187.

\section{REFERENCES}

[1] Camp, T. The Incredible Shrinking Pipeline. Communications of the ACM. 40(10). Oct 1997. 103-110.

[2] Nienaltowski, M., Pedroni, M., \& Meyer, B. Compiler Error Messages: What Can Help Novices? Proc. $39^{\text {th }}$ SIGCSE Technical Symposium, Portland, OR, 168-172.

[3] Head, C. \& Wolfman, S. Poogle and the Unknown-Answer Assignment: Open-ended, Sharable CS I Assignments. Proc. $39^{\text {th }}$ SIGCSE Technical Symposium, Portland, OR, 133-137.

[4] Braught, G., Eby, L., \& Wahls, T. The Effects of PairProgramming on Individual Programming Skill. Proc. $39^{\text {th }}$ SIGCSE Technical Symposium, Portland, OR. 200-204.

[5] Beck, L. \& Chizik, A. An Experimental Study of Cooperative Learning in CS I. Proc. $39^{\text {th }}$ SIGCSE Technical Symposium, Portland, OR. 205-209.

[6] Ma, L., Ferguson, J., Roper, M.m Ross, I. \& Wood, M. Using Cognitive Conflict nd Visualization to Improve Mental Models Held by Novice Programmers. Proc. $39^{\text {th }}$ SIGCSE Technical Symposium, Portland, OR. 342-346.

[7] Dodds, Z., Libeskind-Hadas, R., Alvarado, C. \& Kuenning, G. Evaluating a Breadth-First CS I for Scientists. Proc. $39^{\text {th }}$ SIGCSE Technical Symposium, Portland, OR. 266-270.

[8] Jin, W. Pre-Programming Analysis Tutors Help Students Learn Basic Programming Concepts. Proc. $39^{\text {th }}$ SIGCSE Technical Symposium, Portland, OR. 276-280.

[9] Beyes, S. and Haller, S. Gender differences and intra-gender differences in computer science students: Are female CS majors more similar to male CS majors or female nonmajors? Journal of Women and Minorities in Science and Engineering, 12 337-365, 2006 